\title{
CERVICAL ESOPHAGOGASTRIC ANASTOMOSIS FISTULA FOLLOWING ESOPHAGECTOMY: A PROBLEM WITH NO SOLUTION?
}

\author{
FÍSTULA DA ANASTOMOSE ESOFAGOGÁSTRICA CERVICAL \\ APÓS ESOFAGECTOMIA: UM PROBLEMA SEM SOLUÇÃO? \\ Flavio Roberto TAKEDA $^{1 \oplus}{ }^{,}$, Rubens Aissar SALLUM ${ }^{1 \oplus}$, Ivan CECCONELLO $^{1 \oplus}$, Sérgio Carlos NAHAS ${ }^{1 \oplus}$
}

$\mathrm{T}$ he surgical treatment of esophageal cancer has evolved a lot in recent years. Forty years ago, the esophagectomy with lymphadenectomy technique in three dissection fields (cervical, thoracic and abdominal) proposed by Hiroshi Akiyama in $1981^{1}$ showed an increased survival of patients with esophageal neoplasia associated with extensive lymphadenectomy, currently representing the primary type of esophagectomy performed in the East. However, the surgical procedure's morbidity rate was around $60 \%$, with mortality of around $7 \%{ }^{1}$. The advent of minimally invasive surgery in the late 1990s led to declining rates of postoperative complications, especially those of respiratory complications ${ }^{6}$. The publication of a prospective study comparing the hybrid minimally invasive esophagectomy technique with the conventional esophagectomy technique (thoracotomy and laparotomy) evidenced that the minimally invasive technique could have fewer postoperative complications without interfering with overall survival ${ }^{4}$

In 1977, Professor Henrique Walter Pinotti proposed the transhiatal, also called transdiaphragmatic esophagectomy ${ }^{5}$. This esophagectomy procedure without thoracotomy showed a $40 \%$ decline in surgery-related complications ${ }^{5}$. More recently, performing the same procedure with the minimally invasive technique also showed a decrease of around $20 \%{ }^{7}$.

Thus, in recent years, we observed an improvement in surgical results with acceptable rates of complications ${ }^{10}$. However, when evaluating the surgical results, transthoracic esophagectomy shows more extensive lymphadenectomy related to a more significant number of resected lymph nodes. In the past, this would translate into a direct increase in patient survival. Nowadays, with the advent of neoadjuvant therapies, the need for extensive lymphadenectomy has become very debatable in the literature. Transthoracic access allows resection ${ }^{1}$ of lymph nodes with a median of around 30, while conventional transhiatal access ${ }^{7}$ reaches 20 lymph nodes and laparoscopic transhiatal access 25 lympho nodes ${ }^{3}$.

However, despite the implementation of minimally invasive techniques, the rates of esophagogastric anastomosis fistula remain at around $10-15 \%{ }^{3}$, regardless of the technique employed (manual, circular or linear stapling) and some surgical maneuvers (epiploplasty, pleural reconstruction, and use of surgical glue $)^{2}$

Recently, we proposed a surgical standardization following esophagectomy for revascularization of the gastric tube transposed by the posterior mediastinum using neck vessels (external jugular vein and transverse cervical artery), observing a proven improvement in local tissue perfusion, which reduced the occurrence of $10.4 \%$ of fistulas (control group) to no fistula (the group with microanastomosis) ${ }^{8}$. It is worth mentioning the technical difficulty of assessing tissue perfusion ${ }^{9}$. After all, the methodology employed should be technically easy to apply, as sensitive as possible, and reproducible, which is still a challenge. Probably, esophagogastric fistulas are not only related to tissue perfusion but also local factors such as, for example, hypertension caused by persistent postoperative cough and immunogenic factors.

Finally, cervical vascular microanastomosis (Supercharged Anastomosis For Esophagectomy - SAFE procedure) is a new perspective of reducing esophagogastric fistulas following esophagectomy. The next step will be to identify who would really benefit from SAFE, proven through randomized clinical trials. 
REFERENCES

1. Akiyama $H$, Tsurumaru $M$, Kawamura $T$, Ono Y. Principles of surgical treatment for carcinoma of the esophagus: analysis of lymph node involvement. Ann Surg. 1981;194(4):438-46. doi: 10.1097/00000658-198110000-00007.

2. Castro PM, Ribeiro FP, Rocha Ade F, Mazzurana M, Alvarez GA. Hand-sewn versus stapler esophagogastric anastomosis after esophageal ressection: systematic review and metaanalysis. Arq Bras Cir Dig. 2014;27(3):216-21. doi: 10.1590/ s0102-67202014000300014.

3. Chevallay M, Jung M, Chon SH, Takeda FR, Akiyama J, Mönig S. Esophageal cancer surgery: review of complications and their management. Ann N Y Acad Sci. 2020;1482(1):146-162. doi: 10.1111/nyas. 14492

4. Mariette C, Markar SR, Dabakuyo-Yonli TS, Meunier B, Pezet D, Collet $D, D^{\prime}$ Journo XB, Brigand $C$, Perniceni T, Carrère N, Mabrut JY, Msika S, Peschaud F, Prudhomme M, Bonnetain F, Piessen G; Fédération de RechercheenChirurgie (FRENCH) and French Esophago-Gastric Tumors (FREGAT) Working Group. Hybrid Minimally Invasive Esophagectomy for Esophageal Cancer. N Engl J Med. 2019;380(2):152-162. doi: 10.1056/NEJMoa1805101.
5. Pinotti HW, Pollara WM, Raia AA. Surgical treatment of advanced megaesophagus bysub-total esophagectomy bycervico-abdominal route without thoracotomy with incision of the diaphragm. AMB Rev Assoc Med Bras. 1980;26(10):339-42.

6. Swanstrom LL, Hansen P(1997) Laparoscopic total esophagectomy. Arch Surg 1997;132(9):943-7; discussion 947-9. doi: 10.1001/ archsurg.1997.01430330009001.

7. Takeda FR, Sallum RAA, Ribeiro U Jr, Cecconello I. Laparoscopic transhiatal esophagectomy in esophageal cancer patients with highrisk post-operative complications. Dis Esophagus. 2021:doab022. doi: 10.1093/dote/doab022.

8. Takeda FR, Tutihashi R, Tustumi F, Sallum RAA, de Freitas Busnardo F, Ribeiro U Jr, Cecconello I. Supercharged cervical anastomosis for esophagectomy and gastric pull-up. J Thorac Cardiovasc Surg. 2021;162(3):688-697.e3. doi: 10.1016/j.jtcvs.2020.06.021.

9. TakedaFRDr, Cecconellol. The complexassessment of anastomosis' perfusion following esophagectomy: Set in stone? Eur J Surg Oncol. 2021;47(6):1491-1492. doi: 10.1016/j.ejso.2020.11.010.

10. Vieira FM, Chedid MF, Gurski RR, SchirmerCC, Cavazzola LT, Schramm RV, Rosa ARP, Kruel CDP. Transhiatalesophagectomyin squamouscell carcinoma of the esophagus: what are the best indications? Arq Bras Cir Dig. 2021;33(4):e1567. doi: 10.1590/0102-672020200004e1567. 